\title{
Biochemical variation and association of Maternal Lipid Profile with Body Mass Index during Pregnancy
}

\author{
Satyam Prakash ${ }^{1 *}$ and Dipendra Raj Pandeya ${ }^{2}$ \\ ${ }^{1}$ Department of Biochemistry, Singhania University, Rajasthan, India \\ ${ }^{2}$ Department of Biochemistry, Nepalese Army Institute of Health Sciences, Kathmandu, Nepal
}

*Corresponding author: Satyam Prakash, PhD Scholar, Department of Biochemistry, Singhania University, Pacheri Bari, Jhun Jhunu, Rajasthan, India. Email: sprakashy2424@gmail.com

Received Date: October 01, 2019

Published Date: November 12, 2019

\section{Abstract}

Background and objectives: The alteration of lipid profiles of healthy gestating women occurs with multiple physiological changes which may have subsequent risk associated with adverse pregnancy outcomes affecting both maternal and fetal health. Therefore, the objective of this study was focused to examine serum lipid profile and its correlation with body mass index in pregnant women and healthy non-pregnant women at Terai in Province No.2 of Nepal.

Methods: Cluster random sampling was adopted for this case-control study which was carried out in Department of Biochemistry at Clinical Pathology Laboratory, Janaki Medical College Teaching Hospital, Tribhuvan University, Nepal. BMI was calculated and all the lipid measurements (TC, TG, HDL-C, LDL-C, VLDL-C) were performed on semi-automatic biochemical analyzer measured by standard clinical laboratory techniques. Data was analyzed using SPSS version 20, associations were assessed by Chi-square tests and one-way ANOVA. P-value $(\mathrm{p}<0.05)$ was considered as statistically significant.

Results: $\mathrm{BMI}$ in pregnant women increases with the trimester of pregnancyand was statistically significant $(\mathrm{F}=50.14, \mathrm{p}=0.000)$. The mean level with standard deviation for TC $(215.33 \pm 27.35,226.16 \pm 27.93,247.82 \pm 33.23 ; \mathrm{F}=48.00, \mathrm{p}=0.000), \mathrm{TG}(107.85 \pm 31.11,142.51 \pm 25.66,157.32 \pm 41.80 ; \mathrm{F}=42.05$, $\mathrm{p}=0.000)$,LDL-C $(148.67 \pm 27.24,154.43 \pm 29.61,174.93 \pm 31.50 ; \mathrm{F}=35.11, \mathrm{p}=0.000)$, HDL-C $(45.53 \pm 14.64,43.17 \pm 11.13,41.42 \pm 9.92 ; \mathrm{F}=1.07, \mathrm{p}=0.360)$, $\operatorname{VLDL}-\mathrm{C}(21.57 \pm 6.22,28.50 \pm 5.13,31.46 \pm 8.36 ; \mathrm{F}=42.05, \mathrm{p}=0.000)$ were in $1^{\text {st }}, 2^{\text {nd }}$ and $3^{\text {rd }}$ trimesters of pregnancy respectively. Also, there was positive correlation between BMI with TC, TG, LDL-C, VLDL-C. It was found highly significant $(r=0.226 ; p<0.01, r=0.318 ; p<0.01, r=0.275 ; p<0.01$, $r=0.316 ; p<0.01)$ respectively. However, the relationship between BMI with HDL-C was negatively correlated and found to be significant ( $r=-0.114$; $\mathrm{p}<0.01)$.

Conclusion: The BMI and serum concentrations of TC, TG, LDL-C and VLDL-C were found to be increased in pregnant women except for HDL-C with advancement of gestational trimesters. But, serum TG and VLDL-C was decreased in $1^{\text {st }}$ trimester of pregnancy as compared with non-pregnant healthy women. The relationship between BMI and lipid profile was positively correlated and highly significant for all the blood lipid profile except for HDL-C. However, there was negative correlation between BMI and HDL-C and was found to be significant. Gynecologists should recommend blood lipid profile to be integrated as routine investigation during antenatal care visits to avoid future complications in both mother and fetus.

Keywords: Body mass index, Lipid profile, Pregnancy, Terai.

\section{Introduction}

Mothers are the incarnation of nature. During pregnancy, the extra energy is provided by increased demand of carbohydrates and lipids for the normal development of growing fetus. Maternal circulating cholesterols and free fatty acids (FFAs) are important substrates for both mother and the fetus [1]. Lipogenesis with extra accumulation of fat in body occurs in early pregnancy whereas in later stages of pregnancy increased breakdown of fat helps in fetal development. The energy provided by lipid is used in cellular proliferation of uterus, blood volume expansion of mother, implantation of fetus in uterus, uteroplacental, and fetal development [2]. Maternal plasma lipids are significantly elevated during pregnancy which is affected by maternal hormonal changes as rise in insulin, progesterone, $\beta$-estradiol and human placental lactogen [3]. Alteration in hormones during pregnancy results in changes of serum lipids, usually levels of lipids revert to normal shortly after delivery [4]. 
For non-pregnant individuals, the recommendations for healthy concentrations of blood lipids are below $5 \mathrm{mmol} / \mathrm{L}$ for total cholesterol (TC), below $3 \mathrm{mmol} / \mathrm{L}$ for low-density lipoprotein cholesterol (LDL-C), below $2 \mathrm{mmol} / \mathrm{L}$ for triglycerides (TG), above $1 \mathrm{mmol} / \mathrm{L}$ for high-density lipoprotein cholesterol (HDL-C), below $1.7 \mathrm{mmol} / \mathrm{L}$ for very low density lipoprotein cholesterol (VLDL-C) [5]. From the $12^{\text {th }}$ week of pregnancy, lipid parameters including TC, TG, LDL-C, VLDL-C, HDL-C and phospholipids gradually increase, especially in the second and third trimesters [6].

Analytically, the major increase of the serum TC concentration occurs $25-50 \%$ in the second trimester. The serum TG concentration increases more intensively than the others and its major increase occurs about $200-300 \%$ during the third trimester [7]. The average serum LDL-C concentration increases by about $0.80 \mathrm{mmol} / \mathrm{L}$ in the second trimester compared with the first trimester and $0.69 \mathrm{mmol} / \mathrm{L}$ in the third trimester compared with the second trimester [8]. Serum HDL-C concentration increases during the second trimester but decreases during the third trimester whereas VLDL-Cholesterol increased in both second and third trimester [9].

Maternal factors such as body mass index(BMI), maternal weight gain, maternal nutrition, pre-pregnancy lipid levels and various medical complications of pregnancy may also have significant effects on lipid metabolism and plasma levels [10]. During normal pregnancy, women show an increase in lipid levels, including levels of TG and TC as gestational age progresses [11]. Both TG and TC are taken up by the placenta and are metabolized and transported to the fetus in various forms shows that both lipids are essential for the development of the fetus [12]. However, high levels of maternal TC and TG are associated with cardiovascular risks [13,14], preterm birth (PTB) [15,16], pregnancy-induced hypertension (PIH) [17], preeclampsia [18] and large for gestational age (LGA) [19].

Conversely, decreased levels of TC during pregnancy are associated with PTB [20] and an increased risk of the infant to be born small for gestational age (SGA) [21]. Maternal hypertriglyceridemia is a characteristic feature during pregnancy and corresponds to an accumulation of triglycerides not only in VLDL-C but also in LDL-C and HDL-C. The pregnant women are affected by a type VI hyper-triglyceridemia, according to the Fredrickson/ WHO classification of hyperlipoproteinemias, with an increase in chylomicrons and VLDL-lipoproteins. This subtype is characterized by the presence of hyper - triglyceridemia associated with hypercholesterolemia [22]. Despite these findings, there are still some controversies on the relationship between maternal lipid disturbances and certain pregnancy complications or perinatal outcomes [23,24].

Efficacy of safe motherhood programme is exacerbated due to several hindrances in practical aspects at grass root level. Nepal Demographic and Health Survey 2011 revealed that only half of pregnant women in Nepal managed to attend four Antenatal Care (ANC) visits as recommended, about two-thirds of births (63\%) took place at home, and only $45 \%$ of the mothers had postnatal visits [25]. There is still a huge gap in the provision of equitybased maternal and child health services in rural Nepal due to illiteracy, low socio-economic status, inadequate health service and unawareness of routine checkup during pregnancy.

The alterations of serum lipid indexes are associated with the gestational age. Even though, all the blood lipids naturally increase during pregnancy [26], but they are not routinely measured as part of antenatal care. Evidences of research examining the maternal lipid profile suggests that there is significant relation of elevated lipids during gestation and the hyperlipidemia in late pregnancy may be a purely physiological response to pregnancy or may be indicative of pathology in some women [27]. There is dearth of data on the association between blood lipids with BMI during pregnancy and infant outcomes in Terai region of Nepal. Therefore, this study aimed to investigate serum lipid profile and its correlation with BMI in pregnant women and healthy non-pregnant women at Terai in Province No. 2 of Nepal.

\section{Materials and Methods}

\section{Study design and setting}

This case-control study was carried out in Department of Biochemistry at Clinical Pathology Laboratory in association with Department of Obstetrics and Gynecology, Janaki Medical College Teaching Hospital (JMCTH) from January 2015 to June 2017. It is a medical school established in 2003 A.D located in Kshireshwarnath municipality and with a city hospital at Brahmapuri, Janakpur which runs undergraduate Bachelor of Medicine and Bachelor of Surgery (MBBS), Bachelor of Science in Nursing (B.sc Nursing), Post Basic Bachelor in Nursing (PBBN) programme affiliated to Tribhuvan University (TU), and Proficiency certificate level (PCL) in Nursing affiliated to Council for Technical Education and Vocational Training(CTEVT), Nepal which is regulated by Nepal Medical Council (NMC) and Nepal Nursing Council (NNC) [28,29]. JMCTH is situated in rural area Ramdaiya, Bhawadi of Dhanusha district in Province No. 2 of Nepal.

\section{Study population}

A total of 336 study subjects were selected. Among them, 224 cases (pregnant women) were selected from Janaki Medical College Teaching hospital and antenatal care clinics at sub-metropolitan city, Janakpurdham, Nepal. However, 112 controls (non-pregnant healthy women) were chosen from Marie Stopes Center at the same geographical area. A higher number of cases were decided without compromising the power of study based on available literature and studies [26,30,31]. Cluster random sampling was adopted. Matching was done only for the age variable.

\section{Inclusion Criteria}

Pregnant women of reproductive age confirmed by a validated pregnancy test report and healthy non-pregnant were selected.

\section{Exclusion Criteria}

Pregnant women with gestational diabetes mellitus, hypertension, obesity, and women with other chronic diseases, age above 40 , any physical and mental disability, women who have miscarriage or still birth during recruitment process and woman who were not willing to give consent and participate were excluded. 


\section{Sample Processing}

Venous blood samples were taken after overnight fasting by antecubital venepuncture, under aseptic conditions, from participants in different trimesters of pregnancy. The blood samples were collected in a $3.5 \mathrm{ml}$ vacutainer (BD Plymouth, PL6 7BP, UK, SST II Advance Tubes) and immediately transported to clinical pathology laboratory. $1 \mathrm{ml}$ aliquots of serum samples were obtained by centrifugation (3500rpm for $10 \mathrm{~min}$ at $4^{\circ} \mathrm{C}$ ) and stored at $-20^{\circ} \mathrm{C}$ until analysis.

Every sample was assayed for TC, TG, HDL-C, LDL-C and VLDL-C concentrations. TC was assayed with the cholesterol oxidase-phenol aminophenazone (CHOD-PAP) method. TG was assayed using the glycerol-3-phosphatase oxidase-phenol aminophenazone (GPOPAP) method. HDL-C were measured by homogeneous enzymatic colorimetric assays and LDL-C was calculated by FredericksonFriedwald's formula according to which: LDL-C = TC (mg/dl) HDL-C (mg/dl)- [Trig(mg/dl)/5]. VLDL-C was calculated as $1 / 5$ of Triglycerides [32-34]. The entire lipid measurements were performed on semi-automatic biochemical analyser (Humalyzer 3500) manufactured by Human Diagnostics Uganda, 84 Tufnell Drive, Kamwokya, Kampala, Uganda using clinical chemistry reagent kits supplied by Human Diagnostic Worldwide, MaxPlanck-Ring 21-65205, Weisbaden, Germany.

\section{Data collection}

A structured questionnaire was prepared for interview based on Family Planning Association of Nepal questionnaire and on other international studies with some modifications of Women Health Specialists. The data was collected from study subjects. All participants had their height and weight measured by trained healthcare professionals. The women were weighed with a digital scale (Filizola Ltd., São Paulo, Brazil), and their stature was measured with a Seca Portable Stadiometer (Seca Ltd., Hamburg, Germany).

\section{Results}

Pattern of Age distribution of study participants

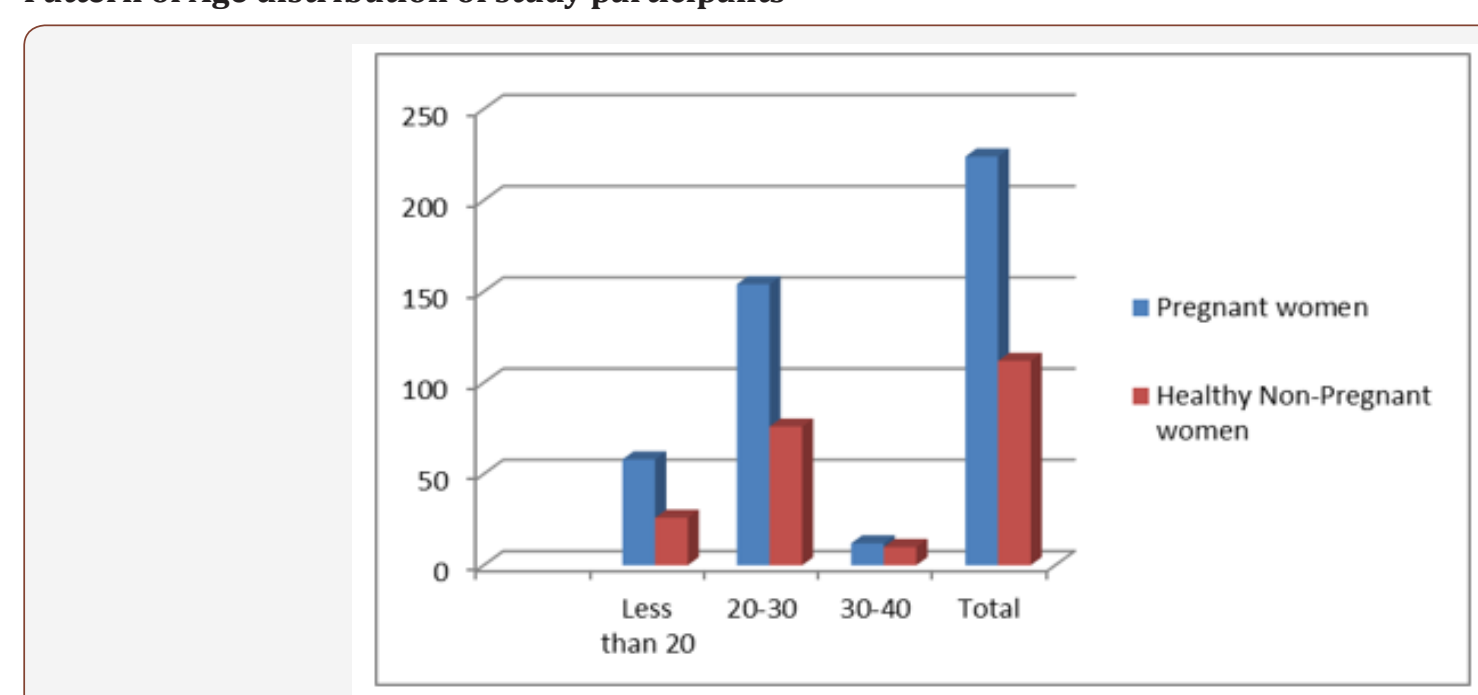

Figure 1: Age wise percentage distribution of participants. 
Of the total 336 women, 224 were pregnant and 112 were non- pregnant. The highest numbers of pregnant and non-pregnant women were in between $20-30$ years age of $69 \%$ and $68 \%$ and lowest in between age of 30-40 years with 5\% and 9\% respectively as shown in Figure 1.

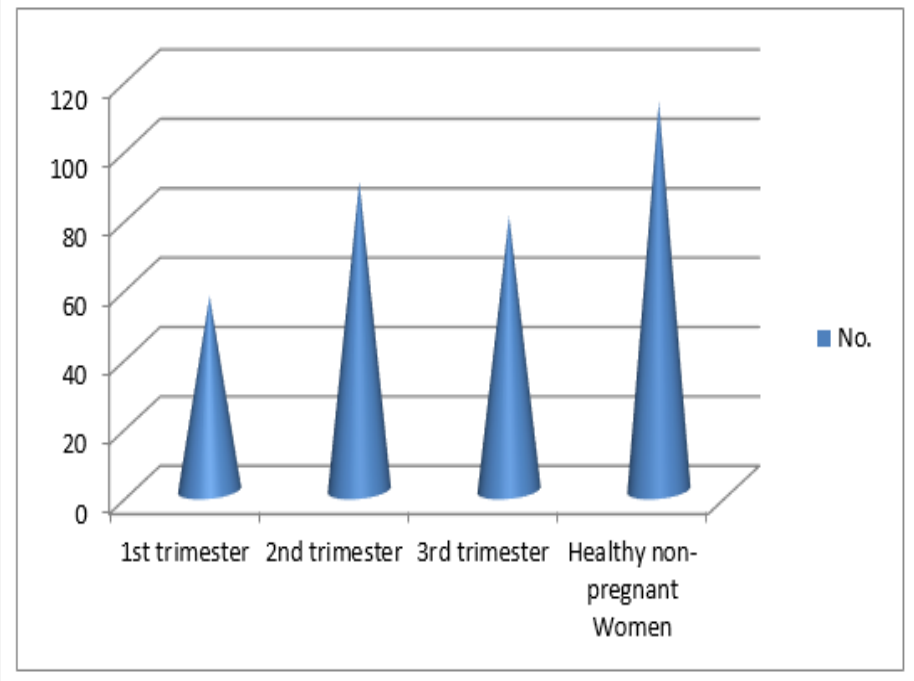

Figure 2: Pattern of study participants according to trimester.

Figure 2 shows among total pregnant women, the greater number of study participants were enrolled in 2nd trimester of pregnancy.

Table 1: Anthropometric measurement of participants.

\begin{tabular}{|c|c|c|c|c|c|c|}
\hline \multirow{2}{*}{ Characteristics } & \multicolumn{3}{|c|}{$\begin{array}{c}\text { Pregnant women (Trimesters) } \\
\text { (n=224) }\end{array}$} & $\begin{array}{c}\text { Healthy Non-Pregnant women } \\
\text { (n=112) }\end{array}$ & F-value & p-value \\
\cline { 2 - 7 } & $1^{\text {st }}$ & $2^{\text {nd }}$ & $3^{\text {rd }}$ & & & \\
\hline Weight & $47.55 \pm 4.46$ & $53.69 \pm 3.14$ & $56.73 \pm 2.84$ & $48.48 \pm 4.08$ & 111.33 & 0.000 \\
\hline Height & $153.66 \pm 7.22$ & $152.57 \pm 6.67$ & $152.51 \pm 7.58$ & $151.96 \pm 7.01$ & 0.71 & 0.545 \\
\hline BMI & $20.24 \pm 2.51$ & $23.18 \pm 2.36$ & $24.53 \pm 2.31$ & $21.10 \pm 2.32$ & 50.14 & 0.000 \\
\hline
\end{tabular}

(BMI-Body Mass Index)

\section{Lipid Profile of participants}

Table 2: Lipid Profile of participants.

\begin{tabular}{|c|c|c|c|c|c|c|}
\hline \multirow{2}{*}{$\begin{array}{l}\text { Lipid Profile } \\
\text { (mg/dl) }\end{array}$} & \multicolumn{3}{|c|}{$\begin{array}{l}\text { Pregnant Women (Trimesters) } \\
\qquad(\mathrm{n}=224)\end{array}$} & \multirow{2}{*}{$\begin{array}{l}\text { Healthy Non -Pregnant women } \\
\qquad(\mathrm{n}=112)\end{array}$} & \multirow{2}{*}{ F-value } & \multirow{2}{*}{ p-Value } \\
\hline & $1^{\text {st }}$ & $2^{\text {nd }}$ & $3^{\text {rd }}$ & & & \\
\hline $\mathrm{TC}$ & $215.33 \pm 27.35$ & $226.16 \pm 27.93$ & $247.82 \pm 33.23$ & $190.68 \pm 39.52$ & 48 & 0.000 \\
\hline $\mathrm{TG}$ & $107.85 \pm 31.11$ & $142.51 \pm 25.66$ & $157.32 \pm 41.80$ & $112.18 \pm 31.49$ & 42.05 & 0.000 \\
\hline LDL-C & $148.67 \pm 27.24$ & $154.43 \pm 29.61$ & $174.93 \pm 31.50$ & $124.72 \pm 41.18$ & 35.11 & 0.000 \\
\hline HDL-C & $45.53 \pm 14.64$ & $43.17 \pm 11.13$ & $41.42 \pm 9.92$ & $43.53 \pm 14.64$ & 1.07 & 0.360 \\
\hline VLDL-C & $21.57 \pm 6.22$ & $28.50 \pm 5.13$ & $31.46 \pm 8.36$ & $22.43 \pm 6.29$ & 42.05 & 0.000 \\
\hline
\end{tabular}

(TC-Total Cholesterol, TG- Triglyceride, LDL-C-Low Density lipoprotein Cholesterol; HDL-C- High Density Lipoprotein Cholesterol; VLDL-C- Very Low-Density Lipoprotein Cholesterol)

Table 2 highlights that TC was progressively increasing trimester wise and found to be elevated in $3^{\text {rd }}$ trimesters accordingly as compared to non-pregnant healthy women. Statistically significant $(\mathrm{p}=0.000)$ relation was found between the case and control. The TG level was decreased in $1^{\text {st }}$ trimester of pregnancy but consequently increased in $2^{\text {nd }}$ and $3^{\text {rd }}$ trimester of pregnancy as compared to control group. The association of TG level among pregnant and non-

\section{Anthropometric measurement of participants}

Table 1 depicts that BMI in pregnant women increases with the trimesters of pregnancy and was statistically significant $(p=0.000)$. 
and was statistically insignificant $(\mathrm{p}=0.360)$. Additionally, the mean level with standard deviation of VLDL-C considerably increased in $3^{\text {rd }}$ trimester of pregnancy with respect to $2^{\text {nd }}, 1^{\text {st }}$ and non-pregnant healthy women respectively. The F-stat value was 42.05 and was statistically significant ( $\mathrm{p}=0.000)$.

Table 3: Correlation between Lipid Profile and BMI ( $N=336)$.

\begin{tabular}{|c|c|c|c|c|c|c|c|}
\hline & & BMI & TC & TG & HDL-C & LDL-C & VLDL-C \\
\hline BMI & Pearson Correlation & 1 & - & - & - & - \\
\hline & Sig. (2-tailed) & - & - & - & - & - & - \\
\hline TC & Pearson Correlation & $.226^{* *}$ & 1 & - & - & - & - \\
\hline & Sig. (2-tailed) & 0 & - & - & - & - & - \\
\hline TG & Pearson Correlation & $.318^{* *}$ & $.447^{* *}$ & 1 & - & - & - \\
\hline & Sig. (2-tailed) & 0 & 0 & - & - & - & - \\
\hline HDL-C & Pearson Correlation & $-.114^{*}$ & -0.026 & $-.141^{* *}$ & 1 & - & - \\
\hline & Sig. (2-tailed) & 0.036 & 0.631 & 0.01 & - & - & - \\
\hline LDL-C & Pearson Correlation & $.275^{* *}$ & $.227^{* *}$ & $.317^{* *}$ & $-.152^{* *}$ & 1 & - \\
\hline & Sig. (2-tailed) & 0 & 0 & 0 & 0.005 & - \\
\hline VLDL-C & Pearson Correlation & $.316^{* *}$ & $.413^{* *}$ & $.425^{* *}$ & -0.044 & $.426^{* *}$ & - \\
\hline & Sig. (2-tailed) & \multicolumn{2}{|c|}{0} & 0 & 0.426 & 0.000 & - \\
\hline
\end{tabular}

\section{Discussion}

Pregnancy is one of the most important periods in human life with hormonal, immunologic, vascular, metabolic and psychological changes in order to nurture and accommodate the developing fetus $[37,38]$. Some of these changes influence normal biochemical values while others may mimic symptoms of medical disease [39].

The current study reflects the maximum number of pregnant and non- pregnant women were in the age between 20-30 years. P-value $(p=0.4332)$ was found to be statistically insignificant. Similar results were obtained by Jin et al. [6] which is analogous to this study. But, in contrast the findings reported by Azab et al., Elzahaf and Omar, Melku and Agmas [40-42] do not match with present study. The differences in results with earlier publications might be due to the variation in the number of study subjects and changes in categorization of age interval.

The other reasons might be the female fertility which is affected by age. The most probable fertile years and reproductive age of woman is 20-30 years and her best reproductive years are in $20 \mathrm{~s}$. The relationship between age and female fertility is sometimes referred to as a woman's "biological clock" [43]. Menarche, the first menstrual period, usually occurs around 12-13 years varies as early and late in different girls. But, after puberty, a woman's fertility peaks in her early and mid-20s female as fertility increases and continues due to regular menstrual cycle. The possibility of ovulation is more apparent as they ovulate regularly each month. Another promising reason of getting pregnant in this age group may be due to high sex drive, heavy sexual pleasure, unprotected intercourse, desire of baby and comfort years to regain the body back into shape.

\section{Correlation between lipid profile and BMI}

The relationship between BMI and lipid profile was positively correlated and highly significant for except HDL-C. There was negative correlation between HDL-C and BMI which was found to be significant $(\mathrm{r}=-0.114 ; \mathrm{p}<0.01)$ as represented in Table 3 .
The present study highlights the lowest number of pregnancies in between of 30-40 years as it is considered as toughest decade for pregnancy which raises the risk of chromosomal abnormalities, miscarriage, hypertension, aneuploidy, loss of ovarian reserve and high-risk pregnancy. Meanwhile, at this age menstrual cycle may grow increasingly irregular and cycles become shorter in late 30 s to early 40 s due to which ovulation skips resulting in missed periods and are no longer to conceive. Fertility in women declines due to normal, age-related changes that occur in the ovaries. The age-related loss of female fertility happens because both the quality and the quantity of eggs gradually decline.

This study emphasizes maximum number of pregnant females were enrolled in $2^{\text {nd }}$ trimester which is not in accord with the study done by Michael et al. [44]. This may be due to the diversity of study population, environmental factors, maximum females from the local area of study setting and reproductive age group.

Gestational weight gain is a strong predictor of short and longterm health outcomes for both childbearing women and their offspring [45]. Obesity during pregnancy has been associated with gestational diabetes, gestational hypertension, pre-eclampsia, birth defects, cesarean delivery, fetal macrosomia, perinatal deaths, postpartum anemia and childhood obesity [46]. The present study established the mean weight in pregnant women was 47.55, 53.69 and 56.73 with standard deviation of $4.46,3.14$, and 2.84 in $1^{\text {st }}, 2^{\text {nd }}$ and $3^{\text {rd }}$ trimester respectively and in healthy non pregnant women were 48.48 with SD of 4.08 . The mean height in pregnant women was $153.66,152.57,152.51$, with standard deviation of 7.22, 6.67, 7.58 in $1^{\text {st }}, 2^{\text {nd }}, 3^{\text {rd }}$ trimesters respectively and in healthy non pregnant women was 151.96 with SD of 7.01. This may be due to fact that 
the mean body weight and the prevalence of obesity increases with each pregnancy by the intake of supplementary nutrients.

Furthermore, high intake of starchy food, fat diet, fried food, drinks, confectionary high in added sugars, large calorie intake with foods high in fat and sugar may be other reasons. Carbohydrates increase blood sugar level and may also develop gestational diabetes. Also, they may have escaped fibre-rich foods or low-calorie diet such as oats, beans, lentils, grains, seeds, variety of fruit and vegetables as well as wholegrain bread and brown rice. Protein-rich dietary supplements lower the risk of child being born underweight, as well as reducing the risk of having a miscarriage [47].

Other prospects might be laziness due to weight gain with reduction in physical activity by avoiding suitable types of exercise including swimming, cycling, brisk walking or at least 30 minutes of a strenuous physical activity on about three to four days per week which are more important to balance and maintain weight during gestational trimesters. The sedentary lifestyle might be the other cause. Knabl et. al. emphasized the body weight also increases with age in the fertile age groups with the average reported weight increase associated with pregnancies ranges from 0.4 to $3.8 \mathrm{~kg}$ compared with pre-pregnancy weights [48]. Preliminary research shows that excessive weight gained in the first trimester predicts excessive weight gain throughout pregnancy. Weight gain during pregnancy has also been shown to have implications for the child's future risk of being overweight as accounted by Waller et. al. [49].

In earlier research the relationships between maternal height and weight with pregnancy complications were extensively explored, but in recent times, BMI is widely accepted as a better measure of over or underweight [50]. Normal pre-pregnancy BMI is protective for adverse pregnancy and neonatal outcomes and has been associated with less obstetrical interventions [51]. Evidence across different obstetric populations is consistent that increased pre-pregnancy BMI associates with increased perinatal morbidity, including obstetrical interventions at birth such as labor induction and surgical deliveries [52,53].

The study highlights mean BMI in pregnant women was 20.24, 23.18 and 24.53 with standard deviation of 2.51, 2.36, and 2.31 in $1^{\text {st }}, 2^{\text {nd }}$ and $3^{\text {rd }}$ trimester respectively and in healthy non pregnant women were 21.10 with SD of 2.32. This depicts that weight and BMI in pregnant women increases with the trimesters of pregnancy and was statistically significant $(\mathrm{p}=0.000)$. But, the association of height between the pregnant and non-pregnant was statistically insignificant $(\mathrm{p}=0.545)$. The rise of BMI advanced with pregnancy was also confirmed by the study carried out by Geraghty et al., and Jin et al. and is quite similar to current study $[6,46]$. The other clarification towards BMI changes may be due to gestational weight gain, hormonal alteration, escaping the regular antenatal care visits, consultation of nutritional therapist, hesitation to ask and take advice from gynecologist.
The higher BMI is believed to increase maternal risk of developing pre-eclampsia [54], gestational diabetes [55], as well as of experiencing still-birth, and neonatal, perinatal, and infant death [56]. High BMIs are generally associated with higher hemoglobin levels during pregnancy; they are associated with an increased risk of postpartum anemia. Pre-eclampsia is approximately twice as prevalent in overweight women (BMI 25 to 30) and approximately three times as high in obese women (BMI greater than 30) [57].

The endogenous female sex hormones have significant effect on serum lipids [58]. Cholesterol levels increase in the second and third trimester of normal pregnancy, but the significance of this is poorly understood. Pregnancy-related endocrine changes (e.g., rising levels of estrogen, progesterone, and cortisol) favor lipogenesis and accumulation of fat associated with hyperphagia [47]. The increased lipid production during pregnancy is necessary as an energy store to fulfill maternal and fetal metabolic needs. However, even temporary maternal hypercholesterolemia in pregnancy is associated with accelerated progression of atherosclerosis in normo-cholesterolemic children [59].

The results of current study revealed the mean TC level (mg/ dl) with standard deviation in $1^{\text {st }}, 2^{\text {nd }}$ and $3^{\text {rd }}$ trimester of pregnancy was $215.33 \pm 27.35,226.16 \pm 27.93$ and $247.82 \pm 33.23$ respectively whereas in non-pregnant healthy women it was $190.68 \pm 39.52$. A similar type of study carried out by Parchwani and Patel reported TC as $182.9 \pm 31.4 ; 222.4 \pm 34.7 ; 251.7 \pm 44.6$ in different trimesters respectively and in control $169.4 \pm 32.6$ [9] also followed same trend parallel to present study. Mean with standard deviation for serum TC as $151.2 \pm 11.1 ; 185.4 \pm 12.5 ; 225.7 \pm 8.9$ in $1^{\text {st }}, 2^{\text {nd }}$ and $3^{\text {rd }}$ trimesters respectively and in control $147.3 \pm 10.2$ was validated by Mishra et al., [2] which is almost in similar pattern as compared to this study. A related study conducted at Mahatma Gandhi Hospital, Navi Mumbai, India accounted the mean cholesterol levels in second and third trimester were $214.6 \pm 18.16 \mathrm{mg} / \mathrm{dl}$ and $242.65 \pm 20.44 \mathrm{mg} / \mathrm{dl}$ respectively which is similar to the present study [60]. Analogous results were elucidated by the evidences of earlier research conducted by Okojie, Diareme et al., Jin et al., Phuse et al., and Geraghty et al., [6,27,61,62].

The elevation in TC is attributed to formation of zygote in the wall of the uterus [2]. One group of researchers finding demonstrates that a mother's serum cholesterol concentrations rise by approximately $50-70 \%$ during pregnancy compared to normal concentrations [63]. Others have reported that, compared to non-pregnant women, estimated total cholesterol concentrations increase up to $39 \%$ in late pregnancy and triglyceride concentrations may be anywhere up to $138 \%$ higher than non-pregnant concentrations in late pregnancy [64]. Evidence has publicized that blood lipids revert to pre-pregnancy levels after delivery which suggests that the elevated serum lipids could play an important role in fetal development [13].

The additional view for elevated TC might be due to intake of high dietary fat, missing proper antenatal care checkup, and avoiding the shared care of specialists as lipidologists, cardiologists 
and obstetricians. But, high cholesterol during pregnancy can lead to pregnancy-induced hypertension, cardiovascular risk which can threaten the life of both the mother and child [65]. The additional increase in cholesterol during pregnancy occurs also in women with familial hypercholesterolemia, in both heterozygotic [66] and homozygotic forms [67]. In contrast, low cholesterol can lead to premature labor and low birth weight [47].

Some previous studies showed that the most dramatic change in the lipid profile in normal pregnancy is serum hypertriglyceridemia, which may be as high as two to three folds in the third trimester over the levels in non-pregnant women [68]. In the present study, the mean TG levels with standard deviation in $1^{\text {st }}, 2^{\text {nd }}$ and $3^{\text {rd }}$ trimester of pregnancy were $107.85 \pm 31.11,142.51 \pm 25.66$ and $157.32 \pm 41.80$ respectively in comparison to control group which was $112.18 \pm 31.49$. The related research noted serum TG as $84.4 \pm 12.2 ; 141.3 \pm 25.1 ; 226.8 \pm 43.5$ in different trimesters respectively and in control $81.3 \pm 15.9$ which is apparently similar to this study [9]. Alike pattern in TG elevation was depicted by Pusukuru et al., in second and third trimester as $188.68 \pm 20.88 \mathrm{mg} /$ $\mathrm{dl}$ and $216.78 \pm 20.09 \mathrm{mg} / \mathrm{dl}$ respectively [60].

A study carried by Mishra et al., [2] reported serum TG as $185.2 \pm 19.3 ; 221.1 \pm 20.7 ; 213.6 \pm 20.2$ in different trimesters and in control 121.1 \pm 15.4 which parallels the result of current study. Okojie, Diareme et al., Jin et al., Phuse et al., and Geraghty et al., Jayanta et al., also outlined identical results for serum TG $[6,27,61,62,69]$. The concentration of serum TG was highest in the $3^{\text {rd }}$ trimester as compared to normal subjects. This may be due to the maternal switch of fuel from carbohydrate to lipid metabolism which is an alternative pathway for production of energy due to high energy demand with increased deposition of lipids and decreased lipolysis [70].

Further, explanation might be added that the rise in triglyceride parallels the rise in estrogen levels i.e. hyperoestrogenemia which induces biosynthesis of endogenous TGs in the liver. This process is associated with hyperinsulinemia in pregnancy. Increased serum levels of insulin in pregnancy lead to an increase in peripheral glucose utilization causing decrease in plasma glucose levels and increased storage of glycogen in tissues [69].

The results obtained in current study for TG concentrations during the late pregnancy are also in line with previous research conducted by Vrijkotte et. al. [71]. It is hypothesized that triglycerides may be used by the developing fetus as a fuel for growth, in addition to glucose [72]. The higher concentrations of triglycerides available in the mother's blood during pregnancy could allow the fetus to develop a larger placenta. Research has shown that the placental capacity for nutrient transfer increases between mid and late gestation with placental surface area for nutrient exchange estimated to increase 5-15-fold [73]. However, in rare cases, women with very high blood levels of triglycerides before pregnancy may develop severely elevated triglycerides placing them at high risk of acute pancreatitis, an uncommon but serious complication which can result in severe abdominal pain and eruptive xanthoma [74].

Human placenta is known to express lipoprotein receptors in high amounts [75]. The rise in LDL-C appears to be necessary for placental steroidogenesis [76]. The present study signifies the mean level of LDL-C was $148.67 \pm 27.24,154.43 \pm 29.61$ and $174.93 \pm 31.50$ in $1^{\text {st }}, 2^{\text {nd }}$ and $3^{\text {rd }}$ trimester of pregnancy respectively whereas in healthy non-pregnant women was $124.72 \pm 41.18$. For LDL-C (mg/dl), another similar study reports $114.1 \pm 20.2$; $132.6 \pm 21.6 ; 154.3 \pm 25.2$ in $1^{\text {st }}, 2^{\text {nd }}$ and $3^{\text {rd }}$ trimester respectively and in control 103.1 \pm 19.2 [9]. The mean LDL-C was estimated as $84.4 \pm 11.2 ; 109 \pm 12.3 ; 138 \pm 12.7$ with advanced pregnancy and in control as $88.3 \pm 11.1$ as depicted in other similar case control study [2] which is in agreement with current findings. Pusukuru et al., estimated the mean LDL-C levels in second and third trimester were $92.41 \pm 18.94 \mathrm{mg} / \mathrm{dl}$ and $137.82 \pm 13.45 \mathrm{mg} / \mathrm{dl}$ respectively [60] which follows the increasing pattern comparable to our study . The results of previous published research $[6,27,60,62,69]$ are in accordance with the present study. Contrarily, Jayanta et al. noticed decrease in LDL-C in normal pregnancy [69] which is contradictory with results of present study.

The elevated levels monitored in present study may be due to environmental factor, luxurious lifestyle and high intake of diets containing saturated, unsaturated and trans-fats during gestational trimesters. Other possibility of increasing LDL-C seems to be a result of the catabolism of an abundant amount of its precursor VLDL-C. High levels of progesterone and estrogen also could be a contributing factor which play augmented role in the increase in LDL-C [58]. It has been recommended that the enhanced LDL-C pattern during pregnancy may be used to recognize women who will develop atherogenic changes later in life [77].

In women of reproductive age, low concentrations of HDL-C are of reflective attention because studies attempting to correlate the risk of coronary heart disease and number of pregnancies have produced paradoxical results $[61,78,79]$. It is witnessed that the decrease in serum HDL-C levels in the third trimester of a normal pregnancy could be a possible threat for developing atherosclerosis [80]. The present study highlights the mean HDL-C level with standard deviation was $45.53 \pm 14.64,43.17 \pm 11.13$ and $41.42 \pm 9.92$ respectively in $1^{\text {st }}, 2^{\text {nd }}$ and $3^{\text {rd }}$ trimester of pregnancy and $43.53 \pm 14.64$ in healthy non pregnant women. Phuse et al. accounted HDL-C to be decreased as compared to control group [62] which is corresponding to our results. The similar results have been reported by various authors in their studies $[6,27,61,62]$.

The decreasing pattern of mean HDL-C levels in second and third trimester was $49.13 \pm 6.15 \mathrm{mg} / \mathrm{dl}$ and $43.07 \pm 4.34 \mathrm{mg} / \mathrm{dl}$ respectively noted in other similar study [60] is almost parallel to existing results. Another similar type of study for HDL-C estimation reports $47.0 \pm 6.3 ; 55.6 \pm 5.5 ; 51.1 \pm 6.3$ in $1^{\text {st }}, 2^{\text {nd }}$ and $3^{\text {rd }}$ trimester respectively and in control $46.7 \pm 5.7$ which differs in $2^{\text {nd }}$ trimester especially but further declination in $3^{\text {rd }}$ trimester [9] is in agreement with this 
study. Parallel findings of HDL-C were also reported by Mankuta et al., [81]. The study conducted at department of Biochemistry at Mayo Institute of Medical Sciences, Barabanki, India reported HDL-C as $49.5 \pm 9.1 ; 49.1 \pm 7.9 ; 52.8 \pm 8.4$; and in control as $46.1 \pm 8.5$ highlights almost same value in $1^{\text {st }}$ and $2^{\text {nd }}$ trimester and inclined in $3^{\text {rd }}$ trimesters [3] which are not in agreement with this study. Also, HDL-C levels did not show any statistically significant alteration as pointed out by Jayanta et al. [69].

The declining changes predicted in present study in HDL-C may be due to the decrease in cholesterol and, to a lesser extent, by some increase in the apolipoprotein A-I content C (apoA-I concentration tends to level off in later pregnancy). As HDL is an unstable and heterogeneous particle with main protein constituent apoA-I, evidence suggests that the ratio of HDL-C to apoA-I may give additional insight as a risk marker not just for CVD but also for all cause and cancer mortality [82]. The other predicting reasons may be due to therapeutic lifestyle changes, less intake of incredibly nutritious diet and escaping physical activity due to increased demands of the growing family over time. Such type of changes in good cholesterol i.e. HDL-C may be a peril for upcoming atherosclerosis.

Earlier Knapp et al. also suggested the possibility of a change in the composition of HDL-C in late pregnancy [83]. The increase in estrogen levels during late pregnancy theoretically should decrease the level of LDL-C [69]. This, however, does not occur and instead, elevations in LDL-C have been observed in this study. This could be due to secondary phenomena caused by increased conversion of the abundant VLDL and increased progesterone level $[69,82]$. Estrogens and progesterone influence HDL-Cholesterol by decreasing and increasing the activity of hepatic lipase respectively [84]. The initial increase in HDL-C is estrogen dependent, while falling HDL-C in the last half of pregnancy, along with LDL-C changes, correlate with rising levels of human placental lactogen, insulin and insulin resistance. Also, high progesterone levels during late pregnancy could be a contributing factor for some decrease in HDL-cholesterol [69].

Additionally, this study revealed the mean level with standard deviation of VLDL-C considerably increased in $3^{\text {rd }}$ trimester of pregnancy as $31.46 \pm 8.36$ with respect to $2^{\text {nd }}, 1^{\text {st }} 28.50 .51 \pm 5.13$ \& $21.57 \pm 6.22$ and non-pregnant healthy women as $22.43 \pm 6.29$ respectively. For VLDL-C $(\mathrm{mg} / \mathrm{dl})$, the related similar study showed $16.2 \pm 3.1 ; 16.8 \pm 5.8 ; 28.2 \pm 8.4 ;$ in $1^{\text {st }}, 2^{\text {nd }}$ and $3^{\text {rd }}$ trimester respectively and in control $45.3 \pm 9.7$ [9] which is likely to this study. The study carried by Pusukuru et al. accounted the mean VLDL-C levels in second and third trimesters were $28.22 \pm 7.66 \mathrm{mg} / \mathrm{dl}$ and $36.27 \pm 6.72 \mathrm{mg} / \mathrm{dl}$ respectively. The results are in accord with present study [60]. VLDL-C was also found to be increased during late pregnancy in earlier two similar researches $[62,69]$ which is parallel to this study.

This is perhaps due to hypertriglyceridemia leading to enhanced entry of VLDL that carries endogenous triglyceride into circulation. The rise in triglyceride rich VLDL-C particles during pregnancy is dependent more on an increased rate of synthesis caused by estrogens than on a decrease in the rate of removal [69]. Interestingly, the binding of VLDL-C to placental membranes exceeds that of LDL, suggesting that the placenta is primarily endowed with receptors that preferentially bind to VLDL-C [85]. In this regard, the VLDL-C/apoE receptor appears to be of particular interest. The localization and regulation of this receptor suggest a major role in placental lipid transport. The effect of placental hormones is to enhance VLDL-C production and decrease hepatic triglyceride lipase activity in the catabolic phase of pregnancy [76].

Many studies have shown an association between BMI and lipid profile had been much discussed during the past decades. Both lipid profile and body fat have been shown to be the important predictors for metabolic disturbances including dyslipidemia, hypertension, diabetes, cardiovascular diseases, hyperinsulinaemia etc. [86]. The present study reveals that there was positive correlation between lipid profile (i.e.TC, TG, LDL-C, HDL-C, VLDL-C) and BMI and was found highly significant $(r=0.226 ; p<0.01, r=0.318 ; p<0.01$, $r=0.275 ; p<0.01, r=0.316 ; p<0.01$ ) respectively. These associations may be due the transfer of maternal cholesterol to the fetus through the umbilical cord. Second, in the course of a normal pregnancy, all lipid and lipoprotein components increased substantially. Another possible reason is that lipid profile might serve as hormonal and nutritional support of a healthy pregnancy $[47,87]$.

Increases in TC and TG levels during pregnancy promote the accumulation of maternal fat stores to serve as a source of calories and a ready source of energy and fatty acids for the mother and the fetus [88]. Moreover, cholesterol is also necessary for uteroplacental vascularization, placental steroid synthesis, and placental transport functions [89]. However, hyperlipidemia is also regarded as an instigator of inflammation and oxidative stress [90]. LDL-C, TC, TG and HDL-C may be involved in the endothelial damage associated with the pathogenesis of preeclampsia. Endothelial dysfunction, mostly associated with oxidation of LDL-C, leads to the formation of glomerular lesions and subsequently proteinuria, which is associated with preeclampsia as well as give an indication of its severity [88].

The study depicts the relationship between HDL-C and BMI was negatively correlated and found to be significant $(r=-0.114 ; p<0.01)$. This may be due to the influence of estrogen and progesterone, rising levels of human placental lactogen, insulin and insulin resistance. Furthermore, this association might be explained directly by the lack of nutrients, resulting in diminished fetal growth or duration of gestation or indirectly through other associated factors such as smoking, poor diet, or medical illness [91]. Lower levels of blood lipids during pregnancy might be also associated with an increased PTB risk. Lower levels of maternal lipids during pregnancy might affect the normal accumulation of maternal fat stores to serve as a source of calories for the mother and fetus. Further, it might affect the placental vascularization and cause shallow placentation, which is associated with sPTB risk $[92,93]$. 


\section{Conclusion}

Maternal hyperlipidemia has been considered as physiological and is not routinely screened during pregnancy. The present study concludes that BMI was increased in pregnant women with the advancement of gestational period. The concentration of serum TC, TG, HDL-C, LDL-C and VLDL-C of pregnant women were elevated in $2^{\text {nd }}$ and $3^{\text {rd }}$ trimester as compared with the normal subjects. The relationship between lipid profile and BMI was positively correlated and highly significant except for HDL-C. Conversely, there was negative association between BMI and HDL-C and found to be significant. The present findings suggests that the maternal lipid profile should be strongly recommended as integrated part of standard guideline of biochemical laboratory investigations in different gestational trimesters to overcome critical problem of heart diseases, pre-eclampsia, GDM, preterm delivery with all the adverse pregnancy outcomes for mother and fetus in both the short and long term.

\section{Acknowledgment}

The authors wish to acknowledge the research department, hospital management, clinical pathology laboratory and Dept. of obstetrics and gynecology, JMCTH, TU, Nepal for providing all the facilities and co-operation during this research. We also debt our special thanks to Dr. Jitendra Kumar Singh, Assoc. Professor, Dept. of Community Medicine and Public Health, JMCTH and Ms. Khushbu Yadav, Medical Microbiologist and Lecturer, Ram Janaki Technical Institute and Hospital, Janakpurdham, Nepal for all their help, support and positive critics for the completion of this research study.

\section{Conflict of Interest}

The authors declared there is no conflict of interest regarding the publication of this manuscript.

\section{Refernces}

1. Brett KE, Ferraro ZM, Yockell Lelievre J, Gruslin A, Adamo KB (2014) Maternal-fetal nutrient transport in pregnancy pathologies: The role of the placenta. Int J Mol Sci 15(9): 16153-16185.

2. Mishra KM, Sharma R, Sharma D, Mishra A, Sharma D (2017) Study of variations in lipid profile in different trimesters of pregnancy. Int J Med Sci Public Health 6(3): 456-459.

3. Alvarez JJ, Montelongo A, Iglesias A, Lasunción MA, Herrera E, et al. (1996) Longitudinal study on lipoprotein profile, high density lipoprotein subclass and postheparin lipases duringgestation in women. J Lipid Res 37(2): 299-308.

4. Roccella EJ (2000) Report of the National High Blood Pressure Education Program Working Group on High Blood Pressure in Pregnancy. American J Obstet \& Gynecol 183(1): S1-S22.

5. Jellinger PS, Smith DA, Mehta AE, Ganda O, Handelsman Y, et al. (2012) American Association of Clinical Endocrinologists' (AACE) guidelines for management of dyslipidemia and prevention of atherosclerosis. Endocr Pract 18: 1-35.

6. Jin YW, Sheng-Liang Lin LS, Hou LS, Chen YX, Han T, et al. (2016) Associations between maternal lipid profile and pregnancy complications and perinatal outcomes: a population-based study from China. BMC Pregnancy Childbirth 16(60): 1-13.

7. Brizzi P, Tonolo G, Esposito F, Puddu L, Dessole S, et al. (1999) Lipoprotein metabolism during normal pregnancy. Am J Obstet Gynecol 181(2): 430434.
8. Martin U, Davies C, Hayavi S, Hartland A, Dunne F (1999) Is normal pregnancy atherogenic? Clin Sci (Lond) 96(4): 421-425.

9. Parchwani D, Patel D (2011) Status of lipid profile in pregnancy. National Journal of Medical Res 1(1): 10-12.

10. Vidyabati KR, Hijam D, Singh KN, Singh GW (2010) Serum ßhCG and lipid profile in early second trimester as predictors of pregnancy induced hypertension. J Obstet Gynaecol India 60(1): 44-50.

11. Ogura K, Miyatake T, Fukui O, Nakamura T, Kameda T, et al. (2002) Low-density lipoprotein particle diameter in normal pregnancy and preeclampsia. J Atheroscler Thromb 9(9): 42-47.

12. Woollett LA (2011) Review: Transport of maternal cholesterol to the fetal circulation. Placenta 32 Suppl 2:S218-S221.

13. Bartels A, Egan N, Broadhurst DI, Khashan AS, Joyce C, et al. (2012) Maternal serum cholesterol levels are elevated from the 1st trimester of pregnancy: a cross-sectional study. J Obstet Gynaecol 32(8): 747-52.

14. Spracklen CN, Smith CJ, Saftlas AF, Robinson JG, Ryckman KK (2014) Maternal hyperlipidemia and the risk of preeclampsia: a meta-analysis. Am J Epidemiol 180(4): 346-58.

15. Laughon SK, McLain AC, Sundaram R, Catov JM, Buck Louis GM (2014) Maternal lipid change in relation to length of gestation: A prospective cohort study with preconception enrollment of women. Gynecol Obstet Investig 77(1): 6-13.

16. Mudd LM, Holzman CB, Catov JM, Senagore PK, Evans RW (2012) Maternal lipids at mid-pregnancy and the risk of preterm delivery. Acta Obstet Gynecol Scand 91(6): 726-735.

17. Jan MR, Nazli R, Shah J, Akhtar T (2012) A study of lipoproteins in normal and pregnancy induced hypertensive women in tertiary care hospitals of the North West Frontier Province-Pakistan. Hypertens Pregnancy 31(2): 292-299.

18. Kandimalla BH, Sirjusingh A, Nayak BS, Maiya SS (2011) Early antenatal serum lipid levels and the risk of pre-eclampsia in Trinidad and Tobago. Arch Physiol Biochem 117(4): 215-221.

19. Kushtagi P, Arvapally S (2009) Maternal mid-pregnancy serum triglyceride levels and neonatal birth weight. Int J Gynaecol Obstet 106(3): 258-259.

20. Edison RJ, Berg K, Remaley A, Kelley R, Rotimi C, et al. (2007) Adverse birth outcome among mothers with low serum cholesterol. Pediatrics 120(4): 723-733.

21. Catov JM, Ness RB, Wellons MF, Jacobs DR, Roberts JM, et al. (2010) Prepregnancy lipids related to preterm birth risk: the coronary artery risk development in young adults study. J Clin Endocrinol Metab 95(8): 3711-3718.

22. Hillman L, Schonfeld G, Miller JP, Wulff G (1975) Apolipo proteins in human pregnancy. Metabolism 24(8): 943-952.

23. Ryckman KK, Spracklen CN, Smith CJ, Robinson JG, Saftlas AF (2015) Maternal lipid levels during pregnancy and gestational diabetes: a systematic review and meta-analysis. BJOG 122(5): 643-651.

24. Savona Ventura C, Vassallo J, Craus J, Anastasiou E, Jotic A, et al. (2016) Biological and biochemical characteristics of a Mediterranean population with Gestational Diabetes Mellitus. J Perinat Med 44(4): 377-382.

25. Ministry of Health and Population, New ERA, ICF International (2012) Nepal Demographic and Health Survey 2011 Kathmandu, Nepal and Calverton, Maryland. USA: Ministry of Health and Population, New ERA and ICF International.

26. Lippi G, Albiero A, Montagnana M, Salvagno GL, Scevarolli S, et al. (2007) Lipid and lipoprotein profile in physiological pregnancy. Clin Lab 53(34): 173-177.

27. Diareme M, Karkalousos P, Theodoropoulos G, Strouzas S, Lazanas N ( 2009) Lipid profile of healthy women during normal pregnancy. JMB 28(3): 152-160.

28. Institutes: Institute of Medicine. Tribhuvan University. Retrieved 14 December 2016. 
29. Recognized Institution - Medical-college. www.nmc.org.np. Retrieved 14 December 2016.

30. Anjum R, Zahra N, Rehman K, Alam R, Parveen A, et al. (2013) Comparative analysis of serum lipid profile between normotensive and hypertensive Pakistani pregnant women. J Mol Genet Med 7(64): 17470862.1000064 .

31. Alavian SM, Esmaillzadeh A, Adibi P, Azadbakht L (2013) Dietary quality indices and biochemical parameters among patients with non alcoholic fatty liver disease (NAFLD). Hepatitis monthly 13(7): e10943.

32. Knopfholz J, Disserol DC, Pierin JA, Schirr LF, Streisky L, et al. (2014) Validation of the Friedewald Formula in Patients with Metabolic Syndrome. Cholesterol 261878: 1-5.

33. Tremblay JA, Morrissette H, Gagn'e MJ, Bergeron J, Gagn'e C, et al. (2004) Validation of the Friedewald formula for the determination of low-density lipoprotein cholesterol compared with $\beta$-quantification in a large population. Clinical Biochemistry 37(9): 785-790.

34. Friedewald TW, Levy IR, Fredrickson DS (1972) Estimation of the concentration of low-density lipoprotein cholesterol in plasma, without use of the preparative ultracentrifuge. Clinical Chemistry 18(6): 499502 .

35. Doherty DA, Magan EF, Francis J, Morrison JC, Newnham JP (2006) Prepregnancy body mass index and pregnancy outcomes. Int J Gynaecol Obstet 95(3): 242-247.

36. World Health Organization (2000) Obesity: preventing and managing the global epidemic. Report of a WHO Consultation. World Health Organ Tech Rep Ser 894: 1-253.

37. Akkoca NA, Ozdemir TZ, Kurt R, Sen BB, Yengil E, et al. (2014) The physiological changes in pregnancy and their distribution according to trimester. Journal of Gynecology and Obstetrics 2(6): 86-90.

38. Prakash S and Yadav K (2015) Maternal Anemia in Pregnancy. Int J Pharm Pharmaceutical Res 4(3): 164-179.

39. Soma-Pillay P, Catherine PN, Tolppanen H, Mebazaa A, Tolppanen H, et al. (2016) Physiological changes in pregnancy. Cardiovasc J Afr 27(2): 89-94.

40. Azab EA, Albasha OM, Elhemady YS (2017) Haematological Parameters in Pregnant Women Attended Antenatal Care at Sabratha Teaching Hospital in Northwest, Libya. Pathology and Laboratory Med 1(2): 6169.

41. Elzahaf RA and Omar M (2016) Prevalence of anaemia among pregnant women in Derna city, Libya. Int J Com Med Public Health 3(7): 19151920.

42. Melku M and Agmas A (2015) Maternal anemia during pregnancy in Bahrdar Town, Northwestern Ethiopia: A facility-based retrospective study. Appl Med Res 1(1): 2-7.

43. Pasqualotto FF, Borges Júnior E, Pasqualotto EB (2008) The male biological clock is ticking: a review of the literature. Sao Paulo Med J 126(3): 197-201.

44. Michael OA, Theresa OA and Tyodoo MM (2017) Haematological Indices of Nigerian Pregnant Women. J Blood Lymph 7(1): 1-4.

45. Herring SJ, Oken E (2010) Weight gain during pregnancy: importance for maternal and child health. Ann Nestle 68: 17-28.

46. Geraghty AA, Alberdi G, O’Sullivan EJ, O’Brien EC, Crosbie B, et al. (2016) Maternal Blood Lipid Profile during Pregnancy and Associations with Child Adiposity: Findings from the ROLO Study. PLoS ONE 11(8): e0161206.

47. Herrera E (2002) Lipid metabolism in pregnancy and its consequences in the fetus and newborn. Endocrine 19(1): 43-55.

48. Knabl J, Riedel C, Gmach J, Ensenauer R, Brandlhuber L, et al. (2014) Prediction of excessive gestational weight gain from week-specific cutoff values: a cohort study. J Perinatol 34(5): 351-356.

49. Waller DK, Shaw GM, Rasmussen SA, Hobbs CA, Canfield MA, et al. (2007) Prepregnancy obesity as a risk factor for structural birth defects. Arch Pediatr Adolesc Med 161(8): 745-750.
50. Bhattacharya S, Campbell DM, Liston WA, Bhattacharya S (2007) Effect of body mass index on pregnancy outcomes in nulliparous women delivering singleton babies. BMC Public Health 7: 168.

51. Vinturache A, Moledina N, McDonald S, Slater D, Tough S (2014) Prepregnancy Body Mass Index (BMI) and delivery outcomes in a Canadian population. BMC Pregnancy and Childbirth 14: 422.

52. Briese V, Voigt M, Wisser J, Borchardt U, Straube S (2011) Risks of pregnancy and birth in obese primiparous women: an analysis of German perinatal statistics. Arch Gynecol Obstet 283(2): 249-253.

53. Arrowsmith S, Wray S, Quenby S (2011) Maternal obesity and labour complications following induction of labour in prolonged pregnancy. BJOG 118(5): 578-588.

54. Wang Z, Wang P, Liu H, He X, Zhang J, et al. (2013) Maternal adiposity as an independent risk factor for pre-eclampsia: a meta-analysis of prospective cohort studies. Obes Rev 14(6): 508-521.

55. Weiss JL, Malone FD, Emig D, Ball RH, Nyberg DA, et al. (2004) Obesity, obstetric complications and cesarean delivery rate-a population-based screening study. Am J Obstet Gynecol 190(4): 1091-1097.

56. Green C, Shaker D (2011) Impact of morbid obesity on the mode of delivery and obstetric outcome in nulliparous singleton pregnancy and the implications for rural maternity services. Aust N Z J Obstet Gynaecol 51(2): 172-174

57. Bodnar LM, Siega-Riz AM, Cogswell ME (2004) High prepregnancy BMI increases the risk of postpartum anemia. Obesity Res 12(6): 941-948.

58. Adegoke OA, Iyare EE, Gbenebitse SO (2003) Fasting plasma glucose and cholesterol levels in pregnant Nigerian women. Niger Postgrad Med J 10(1): 32-36.

59. Huda SS, Sattar N, Freeman DJ (2009) Lipoprotein metabolism and vascular complications in pregnancy. Clin Lipidol 4(1): 91-102.

60. Pusukuru R, Shenoi SA, Yadav KP, Ghodke B, Mehta V, et al. (2016) Evaluation of lipid profile in second and third trimester of pregnancy. Journal of Clinical and Diagnostic Res 10(3): QC12-QC16

61. Okojie FO, Idonije OB, Eseigbe MA, Okhiai O, Unuabonah F, Dike M, et al. (2011) Comparative study of lipid profile of normal pregnant women in the different trimesters. Archives of Applied Science Res 3(3): 528-532.

62. Phuse SS (2012) Effective Study of Lipid Profile during Pregnancy. International J Applied Biotechnology and Biochem 2(4): 381-386.

63. Husain F, Latif SA, Uddin MM (2006) Studies on serum total cholesterol in second and third trimester of pregnancy. J Bangladesh Soc Physiol 1: 1-4.

64. Chiang AN, Yang ML, Hung JH, Chou P, Shyn SK, et al. (1995) Alterations of serum lipid levels and their biological relevance during and after pregnancy. Life Sci 56(26): 2367-2375.

65. Scifres CM, Catov JM, Simhan HN (2014) The impact of maternal obesity and gestational weight gain on early and mid-pregnancy lipid profiles. Obesity (Silver Spring)22(3): 932-938.

66. Glueck CJ, Christopher C, Tsang RC, Mellies MJ (1980) Cholesterol free diet and the physiologic hyperlipidemia of pregnancy in familial homozygous hypercholesterolemia. Metabolism 29(10): 949-955.

67. Tsang RC, Glueck CJ, McLain C, Russell P, Joyce T, et al. (1978) Pregnancy, parturition, and lactation in familial homozygous hypercholesterolemia. Metabolism 27(7): 823-829.

68. Chiang AN, Yang ML, Hung JH, Chon P, Shyn SK, et al. (1995) Alterations of serum lipid levels and their biological relevance's during and after pregnancy. Life Sci 56(26): 2367-2375.

69. De J, Mukhopadhyay A, Saha PK (2006) Study of serum lipid profile inn pregnancy induced hypertension. Indian J Clin Biochem 21(2): 165-168.

70. Herrera E (2001) Metabolic adaptations in pregnancy and their implications for the availability of substrates to the fetus. Eur J Clin Nutr 54 Suppl 1: 547-549.

71. Vrijkotte TG, Algera SJ, Brouwer IA, van Eijsden M, Twickler MB (2011) Maternal triglyceride levels during early pregnancy are associated with birth weight and postnatal growth. J Pediatr 159(5): 736-742. 
72. Kulkarni SR, Kumaran K, Rao SR, Chougule SD, Deokar TM, et al. (2013) Maternal lipids are as important as glucose for fetal growth: Findings from the pune maternal nutrition study. Diabetes Care 36(9): 27062713.

73. Fowden A, Ward J, Wooding F, Forhead A, Constancia M (2006) Programming placental nutrient transport capacity. J Physiol 572(Pt 1): 5-15.

74. (2019) Pregnancy and Blood Fats.

75. Jensen PH, Moestrup SK, Gliemann J (1989) Purification of the human placental alpha 2-macroglobulin receptor. FEBS Lett 255(2): 275-280.

76. Wittmaack FM, Gåfvels ME, Bronner M, Matsuo H, McCrae KR, et al. (1995) Localization and regulation of the human very low-density lipoprotein/apolipoprotein-E receptor: trophoblast expression predicts a role for the receptor in placental lipid transport. Endocrinology 136(1): 340-348.

77. Gunderson EP, Lewis CE, Murtaugh MA, Quesenberry CP, Smith West D, et al. (2004) Long-term plasma lipid changes associated with a first birth: The Coronary Artery Risk Development in Young Adults study. Am J Epidemiol 159(11):1028-1039.

78. Mann JI, Vessey MP, Thorogood M, Doll SR (1975) Myocardial infarction in young women with special reference to oral contraceptive practice. $\mathrm{Br}$ Med J 2(5965): 241-245.

79. Gordon T, Kannel WB, Castelli WP, Dawber TR (1981) Lipoproteins, cardiovascular disease and death. The Framingham Study. Arch Intern Med 141(9): 1128-1131.

80. Bassi R, Kaur M, Sharma S (2011) Study of changes in lipid profile, lipid peroxidation and superoxide dismutase during normal pregnancy. Indian Journal of Fundamental and Applied Life Sci 1(3):249-54.

81. Mankuta D, Elami-Suzin M, Elhayani A, Vinker S (2010) Lipid profile in consecutive pregnancies Lipids Health Dis 9: 58.

82. Piechota W and Staszewski A (1992) Reference ranges of lipids and apolipoproteins in pregnancy. Eur J Obstet Gynecol Reprod Biol 45(1): 21-35.
83. Knopp RH, Warth MR, Charles D, Childs M, Li JR, et al. (1986) Lipoprotein metabolism in pregnancy, fat transport to the fetus, and effects of diabetes. Biol Neonate 50(6): 297-317.

84. Tikkanen MJ, Nikkilä EA (1987) Regulation of hepatic lipase and serum lipoproteins by sex steroids. Am Heart J 113 (2 Pt 2): 562-567.

85. Naoum HG, De Chazal RC, Eaton BM, Contractor SF (1987) Characterization and specificity of lipoprotein binding to term human placental membranes. Biochim Biophys Acta 902(2): 193-199.

86. Sandhu HS, Koley S, Sandhu KS (2008) A Study of Correlation between Lipid Profile and Body Mass Index (BMI) in Patients with Diabetes Mellitus. J Hum Ecol 24(3): 227-229.

87. Jiang S, Jiang J, Xu H, Wang S, Liu Z, et al. (2017) Maternal dyslipidemia during pregnancy may increase the risk of preterm birth: A metaanalysis. Taiwan J Obstet Gynecol 56(1): 9-15.

88. Basaran A (2009) Pregnancy-induced hyperlipoproteinemia: review of the literature. Reprod Sci 16(5): 431-437.

89. Woollett LA (2005) Maternal cholesterol in fetal development: transport of cholesterol from the maternal to the fetal circulation. Am J Clin Nutr 82(6): 1155-1161.

90. Ridker PM (2012) Hyperlipidemia as an instigator of inflammation: inaugurating new approaches to vascular prevention. J Am Heart Assoc 1(1): 3-5.

91. Oluwole AA, Adegbesan-Omilabu MA, Okunade KS (2014) Preterm delivery and low maternal serum cholesterol level: any correlation? Niger Med J 55(5): 406-410.

92. Arias F, Rodriquez L, Rayne SC, Kraus FT (1993) Maternal placental vasculopathy and infection: two distinct subgroups among patients with preterm labor and preterm ruptured membranes. Am J Obstet Gynecol 168(2): 585-591.

93. Germain AM, Carvajal J, Sanchez M, Valenzuela GJ, Tsunekawa H, et al. (1999) Preterm labor: placental pathology and clinical correlation. Obstet Gynecol 94(2): 284-289. 